\title{
Análise do mercado de carbono no Brasil: histórico e desenvolvimento
}

\section{Analysis of the carbon market in Brazil: history and development}

Caroline Soares da Silveira - Engenheira Florestal pela UNIPAMPA. Doutora em Agronegócios pela Universidade Federal do Rio Grande do Sul (UFRGS). E-mail: carolinesoaresef14@hotmail.com

Letícia de Oliveira - Administradora pela Universidade Federal de Lavras (UFLA). Doutora em Agronegócios pela Universidade Federal do Rio Grande do Sul (UFRGS). Professora da Universidade Federal do Rio Grande do Sul (UFRGS). E-mail: leticiaoliveira@ufrgs.br

\section{Resumo}

O objetivo deste estudo foi o de analisar como surgiu e tem se desenvolvido o mercado de carbono e a representatividade do setor florestal brasileiro. Realizou-se um estudo exploratório, contendo dados secundários dos artigos publicados nas bases de dados Scopus, Web of Science, Scielo e Google Acadêmico sobre o mercado de carbono florestal no Brasil. Os resultados deste estudo indicam que o mercado de carbono é um mecanismo que ainda está em regulamentação e possui alguns desafios como o risco e a incerteza dos projetos, principalmente em relação à contabilização do sequestro de carbono e questões institucionais e governamentais. Os estudos sobre mercado de carbono florestal no Brasil foram relacionados a projetos do mecanismo de Redução de Emissões por Desmatamento e Degradação Florestal (REDD+), projetos de Mecanismo de Desenvolvimento Limpo (MDL) (maior proporção), geração de créditos de carbono pela biomassa e estoque de Dióxido de Carbono $\left(\mathrm{CO}_{2}\right)$, projetos de mercado voluntário, Reduções Certificadas de Emissões (RCEs), armazenamento de carbono para o comércio de emissões e redução de emissões de Gases do Efeito Estufa (GEE).

\section{Palavras-chave}

Mercado de Carbono. Sequestro de Carbono. Armazenamento de Carbono. Mudanças Climáticas.

\begin{abstract}
The objective of this study was to analyze how the carbon market and the representativeness of the Brazilian forest sector emerged and has developed. An exploratory study was carried out, containing secondary data from articles published in the Scopus, Web of Science, Scielo and Google Academic databases, on the forest carbon market in Brazil. The results of this study indicate that the carbon market is a mechanism that is still under regulation and has some challenges such as the risk and uncertainty of projects, especially in relation to accounting for carbon sequestration and institutional and governmental issues. Studies on the forest carbon market in Brazil were related to projects of the Reduction of Emissions from Deforestation and Forest Degradation (REDD+) mechanism, Clean Development Mechanism (CDM) projects (greater proportion), generation of carbon credits from biomass and Carbon Dioxide (CO2) inventory, voluntary market projects, Certified Emission Reductions (CERs), carbon storage for emissions trading and reduction of Greenhouse Gas (GHG) emissions.
\end{abstract}

\section{Keywords}

Carbon Market. Carbon Sequestration. Carbon Storage. Climate Change. 


\section{INTRODUÇÃO}

As florestas desempenham papel fundamental na mitigação das mudanças climáticas pelo sequestro e armazenamento de carbono, além da comercialização dos produtos madeireiros, gerando benefícios ambientais e econômicos (OBSERVATÓRIO DO CLIMA, 2015). O plantio de florestas, para comercialização de créditos de carbono, pode aumentar ou manter a rentabilidade no setor florestal, principalmente quando o preço do carbono estiver em alta, visto que o plantio florestal se trata de um investimento de longo prazo, podendo esperar o momento ideal para comercialização (NISHI et al., 2005; OLIVEIRA et al., 2010).

Com os efeitos causados pela concentração de Gases do Efeito Estufa (GEE) na atmosfera, houve a conscientização e incentivo das políticas públicas com o objetivo de reduzir as emissões. Sendo assim, o mercado de créditos de carbono constitui um mecanismo que busca resolver problemas ambientais com uso de ferramentas econômicas, sem que sejam adotadas medidas fiscais (GODOY, 2017). A partir desta discussão, o Protocolo de Quioto foi firmado em 1997 e entrou em vigor em 2005, caracterizado como um acordo internacional que estabelece metas obrigatórias de redução de emissões para os países industrializados (MICHEL; KALLWEIT; VON PFEIL, 2016; UNFCCC, 2021).

Para participar do mercado de carbono foram criados mecanismos de comércio de emissões, surgindo para que as empresas que excedessem os limites de emissões de GEE paguem por projetos de compensação de carbono que, geralmente, são realizados por empresas intermediárias. Os projetos de compensação das emissões de empresas poluidoras, com base no cálculo das emissões associadas às suas operações e estabelecem a compensação, podendo ser comercializados no mercado entre os países (ÀVILA, 2009; UNFCCC, 2008; ZANETTI, 2019).

Dos mecanismos de comércio de emissões, surgiu o estabelecimento de dois tipos de mercados de créditos de carbono no mundo: o oficial (Protocolo de Quioto) e o voluntário (Alternativo). Para o cumprimento das metas do mercado oficial, foram desenvolvidos três mecanismos de flexibilização para comercializar créditos de carbono e ajudar os países a atingirem suas metas de reduções de emissões de GEE e minimizarem os custos dessa redução, são eles: Mecanismo de Desenvolvimento Limpo (MDL), Implementação Conjunta e Comércio de Emissões (MICHEL; KALLWEIT; VON PFEIL, 2016; NAHUR; GUIDO; SANTOS, 2015).

A Implementação Conjunta determina que os países industrializados compensem suas emissões participando de projetos que geram créditos de 
carbono para serem comercializados. O Comércio de Emissões permite que países desenvolvidos negociem entre si os níveis de emissões acordadas no Protocolo. E o MDL afeta diretamente os países em desenvolvimento, determinando que os países industrializados possam cumprir seus compromissos de redução investindo em projetos que evitem as emissões de GEE nos países em desenvolvimento (GODOY, 2013).

Os mercados voluntários são opções frente às exigências e barreiras para algumas atividades no mercado do Protocolo de Quioto. São acessados por indivíduos, empresas e organizações interessadas em mitigar os efeitos das mudanças climáticas (RAMOS; BITTENCOURT; MITKIEWICZ, 2009). Esse mercado pode ser considerado extraoficial e comercializa todo tipo de projeto que se comprometa com a meta de reduzir emissões ou compensá-las (MAT'TEI; ROSSO, 2014).

Portanto, considerando a relevância dos estudos sobre o tema, questionase: como se desenvolveu e quais as potencialidades do mercado de créditos de carbono florestal? Para responder a questão de pesquisa, este estudo objetiva analisar como surgiu e tem se desenvolvido o mercado de carbono e a representatividade do setor florestal brasileiro. Especificamente, busca-se apresentar as informações sobre o surgimento do mercado de carbono; Identificar as questões que influenciam no desenvolvimento deste mercado; e Identificar os estudos sobre o mercado de carbono no Brasil e a representatividade no setor.

A importância deste estudo está na aplicabilidade do mercado de carbono florestal no Brasil, com vistas a identificar o desenvolvimento atual desse mercado e identificar lacunas de estudos futuros (CIFLORESTAS, 2021). Isto se dá principalmente pela problemática das mudanças climáticas e a ameaça às atividades do agronegócio, bem como a preservação dos recursos naturais e o uso múltiplo destes recursos (ASSAD; RIBEIRO; NAKAI, 2019; NOBRE; MARENGO; SOARES, 2019). Portanto, esta revisão pretende contribuir com a literatura, apresentando uma perspectiva clara e atual sobre o funcionamento do mercado de carbono, principalmente no setor florestal brasileiro.

\section{PROCEDIMENTOS METODOLÓGICOS}

Realizou-se um estudo exploratório e bibliográfico, utilizando dados secundários e qualitativos da literatura, interpretados pela análise de conteúdo. A busca dos artigos foi nas Bases de Dados Científica, neste caso o, Google Acadêmico, Web of Science, Scopus e Scielo, utilizando palavras-chave sobre a temática. Nas bases de dados Google Acadêmico e Scielo foram utilizadas as 
seguintes palavras-chave: "Mercado de Carbono", "Crédito de Carbono", "Florestas Plantadas", "Mercado Voluntário" e "MDL". Não foi limitado período para realização da busca nas bases de dados.

Nas bases Web of Science e Scopus foram utilizadas estas palavras-chaves: "Carbon Market", "Carbon Credit", "Cultivated Forest" e "Forest'. O intuito desta busca foi selecionar artigos que apresentassem os marcos históricos e institucionais sobre o mercado de créditos de carbono, relatando os seus principais acontecimentos e a possibilidade da comercialização de créditos de carbono das florestas plantadas. Inicialmente, fez-se a identificação dos artigos que apresentavam informações sobre o surgimento do mercado de carbono e a sua aplicabilidade e os artigos que estudaram projetos de mercado de carbono.

A análise dos dados foi realizada com o Microsoft Excel, com o intuito de organizar as informações e contextualizá-las. A análise de conteúdo foi o método de interpretação das informações selecionadas, que segundo Bardin (2016) é constituída por três fases, quais sejam: pré-análise, exploração do material e tratamento dos resultados. A pré-análise foi iniciada com o estabelecimento dos objetivos, para então prosseguir com a busca dos artigos, iniciar a construção deste estudo e finalmente, a leitura dos resumos. Posteriormente, fez-se a identificação das informações estudadas para a construção desta revisão.

$\mathrm{Na}$ segunda fase da análise de conteúdo, a qual consiste na análise propriamente dita, foi feita a leitura completa dos artigos selecionados na préanálise e coletadas as informações estabelecidas. As informações coletadas foram organizadas para que no tratamento dos resultados, fossem analisadas e interpretadas, conforme será apresentado no tópico a seguir.

\section{RESULTADOS E DISCUSSÃO}

\subsection{HISTÓRICO DO MERCADO DE CARBONO}

O mercado de carbono foi estabelecido alguns anos após o Protocolo de Quioto, na qual surgiu a partir da necessidade de mitigação das mudanças climáticas e os seus efeitos em parâmetros mundiais. Nesse sentido, Zanetti (2019) indica que para compensar o aumento de $\mathrm{CO}_{2}$ causado pelo homem, os sistemas terrestres e aquáticos não são suficientes e podem atingir um ponto de saturação, havendo necessidade de diminuir as emissões. Essas opções de redução e sequestro podem ser realizadas pela mudança da matriz energética e plantios florestais, além de outras práticas industriais. 
O Protocolo de Quioto, que entrou em vigor somente em 2005, consiste em um tratado internacional que estipulou metas de reduções obrigatórias dos principais GEE. Apesar da resistência por parte de alguns países desenvolvidos, foi acordado o "Princípio da Responsabilidade Comum, porém Diferenciada". Assim, os países desenvolvidos e industrializados, por serem responsáveis históricos pela maior parte das emissões e por terem mais condições econômicas para arcar com os custos decorrentes, seriam os primeiros a assumir as metas de redução até 2012 (NAHUR; GUIDO; SANTOS, 2015).

Em 1992, durante a conferência denominada Encontro da Terra, 186 países adotaram a Convenção Quadro das Nações Unidas sobre Mudanças Climáticas (CQNUMC), (United Nations Framework Convention on Climate Change), um acordo mundial cujo objetivo é a estabilização das concentrações dos GEE em um nível que previna a perigosa interferência humana no sistema climático (COSTA, 2004). Sob o princípio da precaução, os países comprometeram-se a elaborar uma estratégia global "para proteger o sistema climático para gerações presentes e futuras" (PBMC, 2014).

Os países também estabeleceram um grupo de acompanhamento das ações voltadas ao tema, a Conferência das Partes (COP), que faz reuniões anuais. A COP é o órgão supremo da CQNUMC que reúne anualmente os países Partes em conferências mundiais. Suas decisões, coletivas e consensuais, de acordo com o PBMC (2014) são tomadas se forem aceitas pelas Partes, sendo soberanas e valendo para todos os países. O objetivo da COP é manter regularmente sob exame e tomar as decisões necessárias para promover a efetiva implementação da convenção e de quaisquer instrumentos jurídicos que a COP possa adotar (MMA, 2019).

Na COP-3, realizada em Kyoto no Japão, em 1997, os países adotaram o Protocolo de Quioto (COSTA, 2004). Já na COP-15, em Copenhague, foi definido um limite aceitável de no máximo $2^{\circ} \mathrm{C}$ na temperatura, como objetivo da Convenção do Clima (PBMC, 2014). Na COP-7 foi formado o "livro de regras" para os mecanismos do Protocolo de Quioto (NAHUR; GUIDO; SANTOS, 2015). Como consequência surgiu o estabelecimento de dois tipos de mercados de carbono no mundo: o oficial, na qual foram desenvolvidos três mecanismos de flexibilização para ajudar os países a atingirem suas metas de reduções: MDL, Implementação Conjunta e Comércio de Emissões e o Voluntário (ZANETTI, 2019).

Após a descrição dos acontecimentos nas principais conferências das Partes, fez-se a sistematização dos principais marcos históricos, construindo uma linha do tempo (Figura 1). 
Figura 1 - Linha do Tempo dos Marcos Históricos a partir da CQNUMC

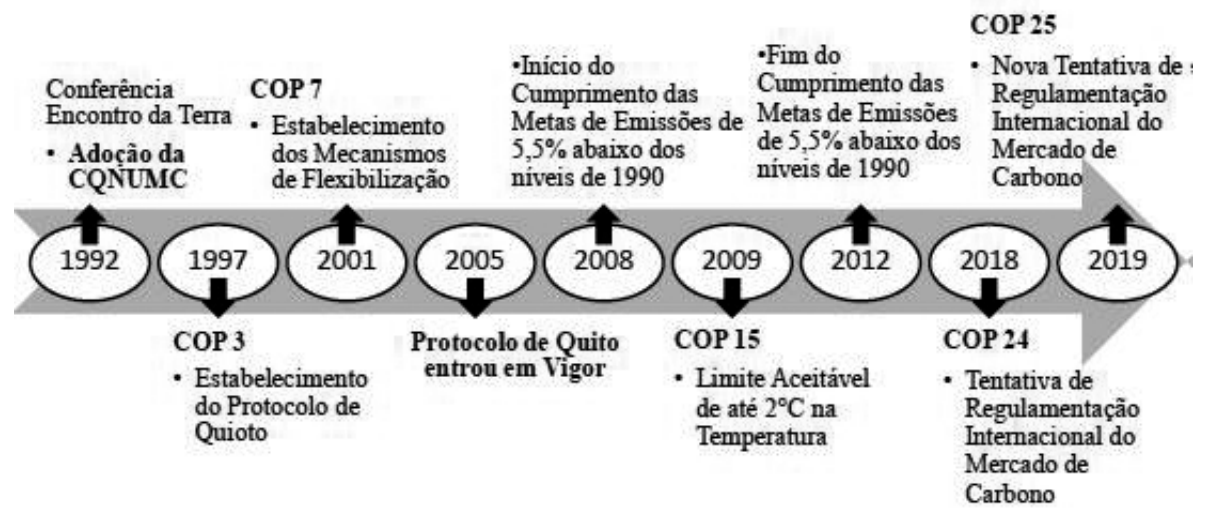

Fonte: organizada pelas autoras, 2021.

Analisando a Figura 1, percebe-se a evolução das discussões sobre as concentrações dos GEE, desde a conferência Encontro da Terra, em 1992. Além disso, observa-se que o princial acordo para mitigação dos GEE foi estabelecido em 1997, porém só entrou em funcionamento no ano de 2005. Antes disso, em 2001 já havia sido estabelecido os mecanismos de flexibilização para cumprir com as metas de redução, que até os dias atuais continua sendo estudado a sua aplicabilidade para uso efetivo. Na COP-24, em 2018, uma das pautas foi a regulamentação internacional do mercado de carbono, porém, não havendo concenso, foi transferido para discussão e implementação na COP-25, no Chile, em 2019.

Os projetos do Protocolo de Quioto são acessados por empreendimentos que buscam reduzir os níveis de emissão de GEE, para aqueles acordados entre os países. De uma forma geral, pode-se dizer que são ações para evitar a imagem negativa de poluidores que os países e as indústrias têm dentro deles. Ademais, até junho de 2007, a redução do desmatamento não era uma modalidade de atividade de projeto elegível no MDL, enquanto projetos de reflorestamento foram aprovados e receberam Reduções Certificadas de Emissões (RCEs) (ZANETTI, 2019).

Os mercados voluntários são opções frente às exigências e barreiras para algumas atividades no mercado do Protocolo de Quioto. São acessados por indivíduos, empresas e organizações interessadas em mitigar os efeitos das mudanças climáticas. Esse mercado pode ser considerado extraoficial e comercializa todo tipo de projeto que se comprometa com a meta de reduzir emissões ou compensá-las. Já o mercado oficial é aquele que têm algum marco regulatório definido e com metas claras de reduções de emissões de 
GEE (MATTEI; ROSSO, 2014). Em 2007, estimou-se que esses mercados movimentaram US\$ 30 bilhões (ZANETTI, 2019).

Passados alguns anos, com a problemática da regulamentação do mercado de carbono, na COP-23, realizada na Polônia, em 2018, uma das pautas foi a tentativa da regulamentação internacional do mercado de carbono. Algumas questões em pauta foram às exigências do Brasil para que houvesse um registro centralizado na Organização das Nações Unidas (ONU) sobre o mercado de carbono, na qual geraram discordância. Uma das preocupações era que os países europeus conseguissem evitar que suas empresas comprassem créditos de carbono fora da União Europeia. O posicionamento brasileiro foi no estabelecimento do Mecanismo de Desenvolvimento Sustentável, na qual terão iniciativas para promover a redução de emissões e poderão ser comercializados como créditos. Porém, o detalhe de como este mercado irá operar não obteve consenso, adiando a discussão para a COP-25, que foi presidida pelo Chile e realizada em Madri, na Espanha, em 2019 (MMA, 2019).

A COP-25, de acordo com a United Nations Climate Change (UNCC, 2020), foi projetada para dar continuidade no processo de mudança climática da ONU, que após o acordo sobre as diretrizes de Implementação do Acordo de Paris na COP-24, objetivou concluir assuntos relacionados à operacionalização, sobretudo para criar ambição antes de 2020, ano em que os países se comprometeram a enviar novos e atualizados planos de ação nacional para o clima. Além disso, uma das metas foi o fechamento do artigo $6^{\circ}$ das regras do Acordo de Paris, que trata dos Mercados Globais de Carbono e foi transferido novamente, para a COP-26.

\subsection{QUESTÕES QUE INFLUENCIAM NO DESENVOLVIMENTO DO MERCADO DE CARBONO}

Das principais questões que influenciaram no desenvolvimento do mercado de carbono, tem-se a crise financeira e econômica mundial de 2008/2009 que atingiu a Europa, na qual, segundo Gusmão et al. (2015) diminuiu os volumes de produção industrial e consequentemente, os níveis de emissão, levando a uma alocação excessiva de permissões e colapso dos preços, afetando a confiança dos investidores e produtores no mercado.

Candeo (2014) aponta que a crise foi consequência, principalmente, da expansão do crédito nos Estados Unidos entre os anos de 2000-2006, da desregulamentação e das inovações financeiras, resultando em uma evolução financeira e endividamento excessivo. Com isso, foi gerado um ambiente de desconfiança e incertezas na economia e o mercado de créditos de carbono 
foi profundamente abalado, pois as mudanças climáticas passaram a ter menos importância perante a prioridade, a recuperação da economia. Com a contração do crédito, houve queda nos investimentos, na demanda, na atividade produtiva, diminuindo assim a emissão de GEE. Ao mesmo tempo, a demanda por créditos de carbono caiu, afetando a oferta e houve queda nos preços dos créditos de carbono.

Conforme Van der Gaast et al. (2018), as florestas e o sequestro de carbono, apesar de ser uma importante atividade para reduzir as emissões de GEE, tiveram uma participação relativamente pequena nos mercados internacionais de emissões. As principais razões para esta pequena participação são o risco e as incertezas desses projetos florestais, na qual são em relação ao monitoramento e precisão dos estoques de carbono, o tempo em que o carbono permanecerá nas árvores, além do risco dos incêndios e o ataque de insetos e pragas.

As mudanças climáticas, que são os principais estímulos para o estabelecimento de florestas para sequestro de carbono, também são um problema de características globais, de longo prazo, envolvendo complexas interações entre processos climáticos, ambientais, econômicos, políticos, institucionais, sociais e tecnológicos, conforme salientado por Costa (2004). O desenvolvimento de respostas às mudanças climáticas, mesmo no âmbito local, é caracterizado por decisões sobre incertezas e riscos. O conhecimento e a comunicação dos riscos e incertezas climáticos são relevantes para o desenho de mecanismos eficientes que evitem a mudança do clima (PBMC, 2014).

Segundo Kunreuther et al. (2014), o risco e a incerteza são fatores que podem afetar o processo e o resultado das escolhas em resposta à ameaça da mudança climática. O risco refere-se ao potencial de efeitos adversos sobre vidas, meios de subsistência, estado de saúde, ativos econômicos, sociais e culturais, serviços (incluindo ambientais) e infraestrutura devido a estados incertos. A incerteza denota um estado cognitivo de conhecimento incompleto que resulta de uma falta de informação e desacordo sobre o que é conhecido.

St-Laurent, Hagerman e Hoberg (2017) indicam a proposta da mitigação das mudanças climáticas pelo plantio florestal e que a implantação de compensações de carbono florestal tem enfrentado vários desafios, especialmente no que diz respeito à sua complexidade e às dificuldades de garantir que eles levem a benefícios climáticos reais. Ideias foram apresentadas para abordar a mudança climática, inclusive a redução das emissões de GEE por meio do uso de novas tecnologias (energia renovável) ou mecanismos econômicos (imposto sobre carbono). Mas, o mais relevante até então, do ponto de vista do movimento climático, foi o potencial das florestas para o sequestro de carbono e as oportunidades econômicas relacionadas ao comércio de emissões. 
Segundo Mattei e Rosso (2014), o mercado de carbono, dentre os demais mercados de serviços ecossistêmicos, é o que detém a maior expressão por conta dos acordos globais apresentados pelo Protocolo de Quioto. No entanto, apenas uma parcela do mercado de carbono corresponde a um serviço ecossistêmico: o mercado de carbono florestal, que ocupa uma parcela ínfima dos recursos transacionados. Porém, esse mercado carece de regulação e, acaba se tornando, basicamente, um mercado voluntário. O mercado de carbono florestal foi o primeiro a ganhar impulso, mas está sendo ultrapassado por outros mercados.

Segundo Reeson, Rudd e Zhu (2015), os serviços de sequestro de carbono podem exigir a participação de vários atores em escalas de governança para atender aos padrões internacionais, além de garantir financiamento de investidores internacionais ou nacionais. Dado que o sequestro de carbono se estende por várias décadas, a incerteza é maior do que em outros usos da terra. Essa incerteza aplicase aos retornos agrícolas e de carbono futuros, a flutuação dos preços de mercado, e a imprevisibilidade dos rendimentos. Entretanto, uma das formas de eliminar a incerteza é a venda direta do carbono no momento do estabelecimento, mas ainda há pouco em termos de mercados futuros de carbono e os contratos geralmente são executados por vários anos, em vez de décadas, como seria necessário.

Conforme analisado por Santos e Vivan (2012), a maior parte dos projetos de pagamentos por serviços ecossistêmicos de carbono no Brasil ainda não possuem certificação e mercado para seus créditos, como exemplificado pelos autores, dependendo muito de recursos de doação para chegar nesse patamar. Aqueles projetos que já vendem seus créditos no mercado de carbono dependem da presença governamental para reduzir custos de transação e tornar os projetos mais eficientes.

Ovando, Beguería e Campos (2018) salientam que existem algumas dificuldades em atribuir valor monetário ao sequestro de carbono florestal, uma vez que as compensações de carbono não possuem mercados bem estabelecidos. Os proprietários de florestas que participam desse mercado devem ser pagos para cada tonelada de $\mathrm{CO}_{2}$ que é removida (apenas pelo crescimento de árvores) e devem pagar um imposto (igual ao preço unitário de permissão de carbono) para retiradas de $\mathrm{CO}_{2}$ devido a incêndios, desbaste e colheita de árvores.

Van der Gaast et al. (2018) identificaram que houve avanços na melhoria das metodologias para a contabilidade de carbono em projetos florestais, especialmente no que tange ao tratamento do risco e da incerteza. Com essas metodologias, os projetos florestais estão mais equipados para entrar nos mercados existentes e emergentes em uma escala que faça jus ao potencial das atividades florestais no cumprimento das metas climáticas e de desenvolvimento socioeconômico e ambiental. 
Além disso, a implantação de florestas para sequestro de carbono, conforme St-Laurent, Hagerman e Hoberg (2017), apresenta algumas barreiras, o que muitas vezes acaba desestimulando os produtores. As principais barreiras identificadas foram em relação aos desafios técnicos, questões mercadológicas, econômicas, direitos de propriedade e questões sociais. Especificando essas barreiras, tem-se o baixo preço do carbono, permanência dos plantios, custobenefício da implantação e a aceitabilidade pública.

O mercado de carbono representa uma nova oportunidade de negócios para o setor rural. Para acessar os mercados de carbono para projetos florestais, é necessário desenvolver atividades de projeto que estejam descritas em um Documento de Concepção do Projeto (DCP) e utilizam metodologia de estimativa e monitoramento de carbono nos plantios. Esses dois passos fundamentais são o que dão acesso a esses benefícios (ZANETT'TI, 2019).

St-Laurent, Hagerman e Hoberg (2017) apontam algumas reflexões e perspectivas para o mercado de carbono. Inicialmente, apesar do progresso do passado, é essencial uma maior inclusão e esclarecimento do direito e propriedade dos benefícios do carbono. É necessário que haja uma estrutura de governança transparente e responsável para que o público apóie os programas de compensação florestal, especialmente quando se espera que um grande comprador das compensações seja o setor público.

Uma das questões mais importantes são as limitações econômicas que diminuem a atratividade para potenciais desenvolvedores de compensações até que ocorra um aumento nos preços do carbono. Embora fossem elaboradas estratégias para melhorar o retorno sobre o investimento e a redução dos custos de transação, os projetos também devem se concentrar na implantação de estratégias integradas de manejo florestal que considerem e agrupem os benefícios além da mitigação do carbono (ST-LAURENT; HAGERMAN; HOBERG, 2017).

Por fim, existe a necessidade da elaboração de projetos do governo com o intuito de convencer os investidores, a sociedade civil e o público-alvo que os projetos de compensação de carbono fornecem reduções de emissões reais, confiáveis e verificáveis, o que pode ser feito com estudos com maior rigor ambiental e científico e, consequentemente, mais onerosos (ST-LAURENT; HAGERMAN; HOBERG, 2017).

No Quadro 1, apresenta-se os desafios para a evolução do mercado de carbono florestal e posteriormente, as indicações de melhorias (oportunidades) que devem ser adotadas para que este mercado seja estabelecido e eficiente, conforme os resultados apresentados nesta seção. 
Quadro 1 - Síntese do Desenvolvimento do Mercado de Carbono Florestal

\begin{tabular}{|c|c|}
\hline Desafios & Oportunidades \\
\hline $\begin{array}{l}\text {-Risco e incerteza dos projetos florestais; } \\
\text {-Complexidade e dificuldade de que } \\
\text { as compensações levem a benefícios } \\
\text { climáticos reais; }\end{array}$ & $\begin{array}{l}\text { Conhecimento e comunicação dos riscos } \\
\text { e incertezas climáticas; } \\
\text {-Avaliação e comunicação dos riscos } \\
\text { econômicos e políticos em relação as } \\
\text { mudanças climáticas; } \\
\text {-Demonstrar a eficácia das ações para } \\
\text { mitigação das mudanças climáticas; }\end{array}$ \\
\hline $\begin{array}{l}\text {-Monitoramento e precisão dos estoques } \\
\text { de carbono; } \\
\text {-Tempo que o carbono permanecerá nas } \\
\text { árvores; } \\
\text {-Risco dos plantios florestais (Incêndio, } \\
\text { pragas e doenças); } \\
\text {-Longo prazo do investimento (Maiores } \\
\text { riscos); }\end{array}$ & $\begin{array}{l}\text {-Implantação de estratégias de manejo } \\
\text { florestal; } \\
\text {-Melhoramento das metodologias para a } \\
\text { contabilidade de carbono, principalmente } \\
\text { no risco e incerteza; }\end{array}$ \\
\hline $\begin{array}{l}\text { Não possuir certificação e mercado para } \\
\text { seus créditos; } \\
\text {-Falta de regulação do mercado de } \\
\text { carbono; } \\
\text {-Instabilidade do preço do carbono; } \\
\text {-Insegurança no investimento pela } \\
\text { flutuação dos preços; } \\
\text {-Dependência de ações governamentais } \\
\text { para reduzir os custos de transação; } \\
\text {-Dificuldade de atribuir valor monetário } \\
\text { ao sequestro de carbono florestal; } \\
\text {-Limitações econômicas que diminuem } \\
\text { a atratividade para potenciais } \\
\text { desenvolvedores de compensações até } \\
\text { que ocorra um aumento dos preços do } \\
\text { carbono. } \\
\text {-Custo-benefício da implantação de } \\
\text { projetos e aceitabilidade pública. }\end{array}$ & $\begin{array}{l}\text {-Venda direta do carbono no momento } \\
\text { do estabelecimento da floresta; } \\
\text {-Desenvolvimento de atividades de } \\
\text { projeto que estejam descritas em um } \\
\text { DCP; } \\
\text {-Maior inclusão e esclarecimento sobre os } \\
\text { direitos de propriedade dos benefícios do } \\
\text { carbono; } \\
\text {-Estrutura governamental transparente e } \\
\text { responsável; } \\
\text {-Elaboração de projetos do governo para } \\
\text { convencer investidores, sociedade civil e o } \\
\text { público-alvo que incentive e demonstre a } \\
\text { eficiência das compensações de carbono. }\end{array}$ \\
\hline
\end{tabular}

Fonte: organizado pelas autoras, 2021.

No Quadro 1, os principais desafios para o estabelecimento do mercado de carbono estão relacionados a diversos fatores, no qual os estudos analisados propõem-se a indicar soluções para estes desafios, traçando oportunidades para este mercado. Os fatores indicados no quadro síntese são detalhados ao longo do texto, permitindo entender o contexto na qual estão inseridos. As oportunidades para o mercado de carbono estão relacionadas com os desafios apresentados em cada um dos três blocos apresentados no quadro 1. O primeiro bloco destaca os 
desafios relacionados às mudanças climáticas, o segundo apresenta os desafios técnicos do plantio florestal e o terceiro em relação aos fatores de mercado e comercialização.

\subsection{OMERCADODECARBONONOBRASILEAREPRESENTATIVIDADE NO SETOR FLORESTAL}

Este tópico apresenta a análise dos estudos sobre mercado de carbono no Brasil e a representatividade no setor florestal, na qual podem ser visualizados no Quadro 2.

Quadro 2 - Estudos e Análises do Mercado de Carbono no Brasil

\begin{tabular}{|c|c|}
\hline Estudo/objetivo/Citação/Ano & Resultados \\
\hline $\begin{array}{l}\text { Mapeamentodas atividades de projetos } \\
\text { de MDL aprovados pela Comissão } \\
\text { Interministerial de Mudanças Climáticas } \\
\text { Globais, a fim de identificar oportunidades } \\
\text { para novos organismos de certificação } \\
\text { (TORRES; FERMAM; SBRAGIA, 2016) }\end{array}$ & $\begin{array}{l}\text { Identificou-se a diminuição no registro de novos } \\
\text { projetos de MDL no Brasil. Os de aterro sanitários } \\
\text { no setor de resíduos foram identificados com maior } \\
\text { potencial para serem explorados. }\end{array}$ \\
\hline $\begin{array}{l}\text { Análise de } 89 \text { projetos de REDD+ no } \\
\text { Brasil (SALLES; SALINAS; PAULINO, } \\
\text { 2017) }\end{array}$ & $\begin{array}{l}\text { Identificou-se que amplas são as } \\
\text { perfil dos projetos, são elas: pra } \\
\text { abrangência, critérios de concessã } \\
\text { práticas de mensuração, relato e ve }\end{array}$ \\
\hline $\begin{array}{l}\text { Quantificação da biomassa e do estoque de } \\
\mathrm{CO}_{2} \text { e avaliação da viabilidade econômica } \\
\text { de créditos de carbono na Área de } \\
\text { Proteção Ambiental da Serra de Baturité- } \\
\mathrm{CE} \text {, além dos mercados de carbono: } \\
\text { MDL e os mercados voluntários Verified } \\
\text { Carbon Stantard - VCS e o esquema de } \\
\text { comércio de Emissões da Nova Zelândia } \\
\text { - NZ ETS (FAJARDO; TIMOFEICZYK } \\
\text { JUNIOR, 2015) }\end{array}$ & $\begin{array}{l}\text { A área de preservação ambiental sequestra em média } \\
84,63 \mathrm{Mt} \text { de CO2 equivalente. No ano de } 2012 \text {, os } \\
\text { projetos florestais para sequestro de carbono geraram } \\
\text { valor anual equivalente de R\$ } 1.336 \text { e TIR de } 21 \% \\
\text { por hectare, se vendido no mercado NZ ETS. No } \\
\text { mercado VCS, a venda dos créditos gera VPL de R\$ } \\
2.138 \text { e TIR de } 18 \% \text {. Entretanto, se os créditos forem } \\
\text { comercializados no MDL, o VPL será de R } \$-702,5 \text {, } \\
\text { concluindo que o projeto é viável nos mercados } \\
\text { voluntários e inviável no mercado regulado. }\end{array}$ \\
\hline $\begin{array}{l}\text { Análise dos co-benefícios em prol do } \\
\text { desenvolvimento sustentável de projetos } \\
\text { do mercado voluntário de carbono no } \\
\text { Brasil (PAIVA et al., 2015) }\end{array}$ & $\begin{array}{l}\text { Identificou-se maior potencial do mercado voluntário } \\
\text { em comparação ao mercado regulado de carbono } \\
\text { para contribuição no desenvolvimento sustentável } \\
\text { em âmbito local, dada sua maior flexibilidade e } \\
\text { a diversidade de atores, assim como a exigência, } \\
\text { por parte de alguns padrões de certificação, } \\
\text { da demonstração do alcance dos cobenefícios } \\
\text { declarados. }\end{array}$ \\
\hline
\end{tabular}




\begin{tabular}{|c|c|}
\hline $\begin{array}{l}\text { Discussão das divergências contábeis } \\
\text { e tributárias das RCEs no mercado } \\
\text { regulado de carbono no Brasil (SOUZA; } \\
\text { ALVAREZ; ANDRADE, 2013) }\end{array}$ & $\begin{array}{l}\text { O mercado regulado de carbono carece de } \\
\text { normatizações, gerando uma diversidade de } \\
\text { classificação e registro contábil dos créditos de } \\
\text { carbono. Tende-se ao reconhecimento como } \\
\text { estoques, uma vez que os benefícios financeiros } \\
\text { gerados com suas vendas podem ser contabilizados } \\
\text { como fator de redução dos custos de produção da } \\
\text { empresa. Sob a ótica tributária, ainda há dúvidas } \\
\text { quanto ao enquadramento das receitas dos créditos } \\
\text { de carbono transacionados com o exterior, dada a } \\
\text { indefinição de sua natureza jurídica. }\end{array}$ \\
\hline $\begin{array}{l}\text { Identificação dos custos de transação } \\
\text { nos projetos de MDL e investigar se eles } \\
\text { são barreiras para o desenvolvimento do } \\
\text { projeto (GODOY, 2013) }\end{array}$ & $\begin{array}{l}\text { A maioria dos projetos com reduções verificadas, } \\
\text { não apresenta desempenho satisfatório. No entanto, } \\
\text { em volume de reduções, a maior parte dos projetos } \\
\text { cumpre mais do que } 91 \% \text { de sucesso de reduções. } \\
\text { Os setores mundiais mais eficientes no Brasil são } \\
\text { N2O e troca de energia fóssil; Os menos eficientes } \\
\text { são os de agricultura e resíduos sólidos. Também } \\
\text { foi identificado que os custos de transação afetam o } \\
\text { sucesso da redução de MDL, e os mais importantes } \\
\text { são os custos ex ante, resultantes de problemas de } \\
\text { falhas de informação e problemas de mensuração. }\end{array}$ \\
\hline $\begin{array}{l}\text { Análise das atividades de Responsabilidade } \\
\text { Social Empresarial (RSE) no MDL em três } \\
\text { países da América Latina, Brasil, México } \\
\text { e Peru, e entender os fatores por trás } \\
\text { dessas iniciativas (BENITES-LAZARO; } \\
\text { MELLO-THÉRY, 2017) }\end{array}$ & $\begin{array}{l}\text { No Brasil, a maioria das atividades se concentra em } \\
\text { "oportunidades locais de emprego". Dos } 341 \text { projetos } \\
\text { analisados, } 271 \text { mencionam atividades relacionadas } \\
\text { à RSE. As principais lições da análise do MDL são } \\
\text { que apesar de todas as críticas, as atividades de RSE } \\
\text { em torno do mecanismo do carbono precisam ser } \\
\text { apreciadas e devem ser enfatizadas em projetos com } \\
\text { os maiores benefícios socioambientais em longo } \\
\text { prazo e devem ser refletidos a um preço mais alto. } \\
\text { Nos projetos de MDL, há falta de monitoramento } \\
\text { e mecanismos de controle para supervisionar se as } \\
\text { atividades planejadas de RSE ou os benefícios para o } \\
\text { desenvolvimento sustentável descrito são realmente } \\
\text { alcançados. }\end{array}$ \\
\hline $\begin{array}{l}\text { Investigação de plantas de MDL, em } \\
\text { nível de empresa, nos setores de açúcar e } \\
\text { cimento no Brasil e na Índia (HULTMAN } \\
\text { et al., 2012) }\end{array}$ & $\begin{array}{l}\text { O MDL opera de maneira mais complexa na } \\
\text { prática. Além disso, embora a receita antecipada } \\
\text { tenha desempenhado um papel central nas decisões } \\
\text { da maioria dos gerentes de buscar investimentos em } \\
\text { MDL, não havia prática padrão para contabilizar os } \\
\text { benefícios financeiros dos investimentos em MDL. } \\
\text { Alguns gerentes identificaram fatores de reputação } \\
\text { não financeiros como sua principal motivação para } \\
\text { a realização de projetos de MDL. Ademais, sob } \\
\text { regimes regulatórios flutuantes com custos reais } \\
\text { imediatos e receita incerta de MDL, os gerentes eram } \\
\text { a favor de projetos que geralmente não exigiam que a } \\
\text { receita de carbono fosse viável. }\end{array}$ \\
\hline
\end{tabular}


Análise das perspectivas das empresas de países em desenvolvimento sobre o mercado de carbono, analisando a sua participação no MDL de usinas de açúcar no Brasil (PULVER; HULTMAN; GUIMARÃES, 2011) ecológica na estrada para armazenamento de carbono e discussão dos impactos ambientais positivos adicionais (FERNANDES et al., 2018)

Desenvolvimento de modelo de programação para formular dietas para gado leiteiro quando houver políticas ambientais e examinar os seus efeitos na formulação da dieta e na excreção de nitrogênio e mineral, bem como nas emissões de metano (MORAES et al., 2012)

Análise das perspectivas de implementação de políticas públicas no Brasil, capaz de promover a interação do desenvolvimento sustentável com a preservação ambiental (SANTANA FREIRE; BRITO, 2016)
As dinâmicas de mercado e não mercadológicas que direcionam os padrões de investimento das usinas de açúcar na redução de carbono. $\mathrm{O}$ acesso a uma fonte confiável de informações foi um dos principais fatores da participação inicial do MDL pelas usinas, ao lado de outros fatores de mercado, como preocupações com receita, custo e reputação. As empresas com relacionamentos pré-existentes com especialistas da indústria de carbono estavam mais dispostas a assumir o risco de participação no mercado de carbono e estavam em uma posição mais favorável para capturar oportunidades precoces em projetos de redução de emissões. Além disso, consultores do mercado de carbono foram os principais agentes das atividades de MDL no setor açucareiro do Brasil.

Enquanto, em muitas regiões do mundo o carbono é uma mercadoria, o Brasil ainda está estudando a implementação de um mecanismo de comércio de emissões. Portando, as conclusões é que um mercado brasileiro de carbono tornaria as ações de restauração florestal mais viável, e esse mercado poderia ser usado para financiar projetos governamentais de restauração de vegetações nas estradas, por exemplo.

Os preços do mercado de crédito de carbono não pareceram onerosos o suficiente para ter um efeito de incentivo substancial na redução das emissões de metano e na alteração dos custos da dieta do rebanho bovino. No entanto, quando se supôs que as emissões de metano fossem reduzidas em 5, 10 e 13,5\% em relação ao modelo base, os custos totais da dieta aumentaram em 5, 19,1 e 48,5\%, respectivamente. Esses custos aumentados seriam repassados ao consumidor ou os produtores de laticínios fechariam o negócio.

Considerando o cenário em que grandes poluentes e empresas devem estabelecer metas de redução de emissões, a criação de um sistema de comércio de emissões de GEE encorajaria outras empresas a reduzir suas emissões e comercializá-las em um mercado regulamentado. Esse modelo é semelhante ao estabelecido pelo Protocolo de Quioto e reproduzido internamente em países como EUA e China. Novas políticas ambientais, com incentivos financeiros, levam os gerentes da empresa a promover a redução de emissões de GEE por meio da inovação e adaptação de processos e produtos. 


\begin{tabular}{|c|c|}
\hline $\begin{array}{l}\text { Apresentação da dinâmica da evolução } \\
\text { dos mercados de carbono em diferentes } \\
\text { mercados e a sua estrutura, desempenho, } \\
\text { potencial e barreiras (GODOY; SAES, } \\
\text { 2015) }\end{array}$ & $\begin{array}{l}\text { São afetados por diversos fatores, resultando em } \\
\text { menor volume de negociação. Esses motivos } \\
\text { podem ser resumidos em preços baixos de créditos } \\
\text { de carbono, incerteza e crise econômica. Algumas } \\
\text { medidas podem beneficiar esses mercados e } \\
\text { contribuir para uma maior eficiência, como: Adoção } \\
\text { de metas de redução mais ambiciosas, alcançando } \\
\text { um número maior de países, melhorias nas } \\
\text { regulamentações de mercado, redução de custos de } \\
\text { transação e disseminação de informações. }\end{array}$ \\
\hline $\begin{array}{l}\text { Análise da geração e a utilização dos } \\
\text { recursos destinados ao Fundo Especial } \\
\text { do Meio Ambiente e Desenvolvimento } \\
\text { Sustentável provenientes das RCEs, } \\
\text { leiloadas em 2007/2008, dos projetos } \\
\text { de MDL implantados nos aterros de SP } \\
\text { (CRUZ; PAULINO, 2013) }\end{array}$ & $\begin{array}{l}\text { Os principais gargalos encontrados foram em relação } \\
\text { a muitas disparidades nos projetos anunciados e } \\
\text { efetivamente executados, além dos anseios das } \\
\text { populações afetadas não terem sido atendidos com } \\
\text { os recursos das reduções certificadas de emissão. }\end{array}$ \\
\hline $\begin{array}{l}\text { Revisão das tendências atuais dos } \\
\text { processos econômicos, ecológicos e } \\
\text { climáticos da Amazônia (NEPSTAD et al., } \\
\text { 2008) }\end{array}$ & $\begin{array}{l}\text { Contrariando as tendências de degradação de } \\
\text { mais da metade das florestas de dossel fechado da } \\
\text { Amazônia até 2030, estão surgindo mudanças no } \\
\text { comportamento dos proprietários de terras. Nesse } \\
\text { sentido, foram identificados sucessos recentes } \\
\text { no estabelecimento de grandes blocos de áreas } \\
\text { protegidas em fronteiras agrícolas ativas e técnicas } \\
\text { práticas para concentrar a produção pecuária em } \\
\text { áreas menores que poderiam reduzir a probabilidade } \\
\text { de uma substituição auto-reforçada em larga escala } \\
\text { de floresta propensa ao fogo. }\end{array}$ \\
\hline
\end{tabular}

Fonte: organizado pelas autoras, 2021.

Iniciando a discussão, fez-se uma síntese dos temas que são abordados nos estudos sobre Mercado de Carbono no Brasil e posteriormente, delimitar a representatividade destes no setor florestal, a partir da frequência dos temas, Os temas foram: Projetos de MDL (40\%), Armazenamento de Carbono para o Comércio de Emissões (13\%), Mercado de Carbono (13\%), Geração de Créditos de Carbono pela Biomassa e Estoque de CO2 (7\%), Projetos de Mercado Voluntário de Carbono (7\%), RCEs no Mercado Regulado de Carbono (7\%), Redução de Emissões de GEE (7\%) e Projetos de REDD+ (6\%).

Dos artigos sobre mercado de carbono analisados, três artigos estudaram questões relacionadas ao setor florestal, apenas. Nestes estudos foi abordada a viabilidade da geração de créditos de carbono em uma área de preservação ambiental, a geração de créditos de carbono em restauração ecológica de estradas e as tendências nos processos econômicos, ecológicos e climáticos da Amazônia.

Entretanto, O Brasil apresenta oportunidades em determinadas áreas para participar ativamente no mercado de carbono. Além da agricultura de 
baixo carbono, energias renováveis, recuperação florestal e restauração de áreas degradadas, o Brasil comprometeu-se com o Acordo de Paris a reflorestar 12 milhões de hectares. Ademais, o país é signatário do desafio de Bonn, onde 39 nações se dispuseram a reflorestar 350 milhões de hectares até 2030 (SANTELLI, 2020). Estas informações de metas do Brasil demonstram a importância das florestas no mercado de créditos de carbono e as oportunidades e os desafios que o país tem de enfrentar nos próximos anos com os acordos climáticos mundiais.

\section{CONCLUSÃO}

O mercado de carbono surgiu com o Protocolo de Quioto em 1997, porém só entrou em vigor em 2005. Os mecanismos de flexibilização, que inclui o MDL, foram estabelecidos em 2001 e a regulamentação do mercado de carbono ainda está em discussão, proposta para a COP-25 em 2019. Os principais desafios do estabelecimento do mercado de carbono estão nos riscos e incertezas dos projetos, principalmente em relação ao sequestro, estoque e contabilização do carbono nas florestas, além das questões institucionais e governamentais.

Os estudos sobre o mercado de carbono no Brasil, identificados neste artigo, são referentes a Projetos de REDD+, Projetos de MDL (maior proporção), Geração de Créditos de Carbono pela Biomassa e Estoque de CO2, Projetos de Mercado Voluntário de Carbono, RCEs no Mercado Regulado de Carbono, Armazenamento de Carbono para o Comércio de Emissões e Redução de Emissões de GEE.

Os projetos de MDL, identificados com maior proporção, apresentaram os seguintes resultados: Diminuição no registro de novos projetos de MDL no Brasil; Dos projetos de MDL, os que têm maior potencial de serem explorados são os de aterro sanitário; A comercialização de créditos no MDL são menos viáveis do que àqueles comercializados no mercado voluntário; O mercado regulado de carbono no Brasil carece de normatizações e possui indefinição jurídica; Os projetos de MDL possuem maiores custos de transação, falhas de informação e problemas de mensuração; Existem dúvidas se os benefícios de desenvolvimento sustentável são alcançados; O MDL opera de forma complexa e não existe prática padrão para contabilizar os benefícios financeiros.

Além disso, apenas três destes estudos referiam-se a estudos sobre o mercado de carbono no setor florestal. Nestes estudos foi abordada a viabilidade da geração de créditos de carbono em uma área de preservação ambiental, a geração de créditos de carbono em restauração ecológica de estradas e as tendências nos processos econômicos, ecológicos e climáticos da Amazônia. 
Por fim, como principal limitação, identificou-se a baixa quantidade de estudos sobre o mercado de carbono florestal, especificamente no Brasil, podendo estar relacionado ao uso das palavras-chave estabelecidas. Por fim, a sugestão de estudos futuros sobre o tema do mercado de carbono está no desenvolvimento de soluções para os principais problemas em relação à aplicabilidade do MDL, na qual foram apresentados no parágrafo anterior.

\section{REFERÊNCIAS}

ASSAD, E. D.; RIBEIRO, R. R. R.; NAKAI, A. M. Assessments and how an increase in temperature may have an impact on Agriculture in Brazil and mapping of the current and future situation. In: NOBRE, C. A.; MARENGO, J. A.; SOARES, W. R. (org.). Climate change risks in Brazil. São Paulo: Spinger Nature, 2019. p. 3-65

ÀVILA, P. R. T. Os impactos financeiros da comercialização dos créditos de carbono em uma empresa florestal: o caso Plantar S/A. 2009. Dissertação (Mestrado Profissional em Administração) - Programa de PósGraduação Profissional em Administração, Faculdades Integradas de Pedro Leopoldo, São Leopoldo, 2009.

BARDIN, L. Análise de conteúdo. São Paulo: Editora 70, 2016.

BENITES-LAZARO, L. L.; MELLO-THÉRY, N. A.CSR as a legitimatizing tool in carbon market: evidence from Latin America's clean development mechanism. Jornal of Cleaner Production, [s. l.], n. 149, p. 218-226, 2017. CANDEO, A. A. A crise econômico-financeira e o mercado de créditos de carbono. 2014. Monografia (Bacharelado em Ciências Econômicas) - Faculdade de Ciências Econômicas, Universidade Federal do Paraná, Curitiba, 2014.

CI FLORESTAS. Ciflorestas, [s. l.], 2021. Disponível em: http://www. ciflorestas.com.br/texto.php?p=carbono. Acesso em: 18 jan. 2021.

COSTA, P. O. Resposta político-econômica às mudanças climáticas: origens, situação atual e incertezas do mercado de créditos de carbono. 2004. Dissertação (Mestrado Profissional em Administração) - Programa de PósGraduação em Administração, Universidade Federal da Bahia, Salvador, 2004.

CRUZ, S. S.; PAULINO, S. R. Local use of resources from clean development mechanism projects in landfill sites in the city of São Paulo. Ambiente e Sociedade, São Paulo, v. 26, n. 1, p. 117-140, 2013. 
FAJARDO, A. M. P.; TIMOFEICZYK JUNIOR, R. Avaliação financeira do sequestro de carbono na Serra de Baturité, Brasil. Floresta e Ambiente, Seropédica, v. 22, n. 3, p. 391-399, 2015.

FERNANDES, G. W.; BANHOS, A.; BARBOSA, N. P. U.; BARBOSA, M.; BERGALLO, H. G.; LOUREIRO, C. G.; OVERBECK, R.; SOLAR, R.; STRASSBURG, B. B. N.; VALE, M. M. Restoring Brazil's road margins could help the country offset its $\mathrm{CO}_{2}$ emissions and comply with the Bonn and Paris Agreements. Perspectives in Ecology and Conservation, [s. l.], v. 16, n. 2, p. 105-112, 2018.

GODOY, S. G. M. Projetos de redução de emissões de gases do efeito estufa: desempenhos e custos de transação. Revista de Administração, São Paulo, v. 48, n. 2, p. 301-326, 2013.

GODOY S. G. M. S. Os mercados de carbono em perspectiva comparada (2017). ICTSD, [s. l.], 2017. Disponível em: https://ictsd.iisd.org/bridgesnews/pontes/news/os-mercados-de-carbono-em-perspectiva-comparada. Acesso em: 28 out. 2018.

GODOY, S. G. M.; SAES, M. S. M. Cap-and-trade and project-based framework: How do carbon markets work for greenhouse emissions reduction? Ambiente e Sociedade, São Paulo, v. 18, p.135-154, 2015.

GUSMÃO, F. et al. Estudos sobre mercado de carbono no Brasil: análise da alocação de permissões. Washington DC: Banco Interamericano de Desenvolvimento: BM\&BOVESPA, 2015. (Monografia do BID; 309).

HULTMAN, N. E.; PULVER, S.; GUIMARÃES, L.; DESHMUKH, R.; KANE, J. Carbon market risks and rewards: firm perceptions of CDM Investment Decisions in Brazil and India. Energy Police, [s. l.], n. 40, p. $90-$ 102, 2012.

KUNREUTHER, H. S.; GUPTA, V.; BOSETTI, R.; COOKE, V.; DUTT, M.; HA-DUONG, H.; HELD, J.; LLANES-REGUEIRO, A.; PATT, E.; SHITTU.; WEBER, E. Integrated risk and uncertainty assessment of climate change response policies. In: EDENHOFER, O.; PICHS-MADRUGA, R.; SOKONA, Y.; FARAHANI, E.; KADNER, S.; SEYBOTH, K.; ADLER, A.; BAUM, I.; BRUNNER, S.; EICKEMEIER, P.; KRIEMANN, B.; SAVOLAINEN, J.; SCHLÖMER, S.; VON STECHOW, C.; ZWICKEL, T.; MINX, J. C. (Ed.) Climate Change 2014: mitigation of climate change. Contribution of Working Group III to the Fifth Assessment Report of the Intergovernmental Panel on Climate Change.Cambridge, UK: Cambridge University Press, 2014. 
MATTEI, L.; ROSSO, S. Evolução do mercado de pagamento por serviços ecossistêmicos no Brasil: evidencias a partir do setor hídrico. Boletim Regional, Urbano e Ambiental - IPEA, Brasília, DF, n. 9, p. 33-48, 2014. MICHEL, J.; KALLWEIT, K.; VON PFEIL, E. The clean development mechanism (CDM). In: PANCEL, L.; KÖHL, M. (Ed.). Tropical Forestry Handbook. Berlim: Springer, 2016. p. 3039-3056.

MMA. Conferência das Partes. Ministério do Meio Ambiente, Brasília, DF, 2019. Disponível em: http://www.mma.gov.br/clima/convencao-das-nacoesunidas/conferencia-das-partes.html. Acesso em: 28 maio 2019.

MORAES, L. E.; WILEN, J. E.; ROBINSON, P. H.; FADEL, J. G. A. Linear programming model to optimize diets in environmental policy scenarios.

Journal of Dairy Science, [s. l.], n. 95, p. 1267-1282, 2012.

NAHUR, A. C.; GUIDO, F. L.; SANTOS, J. A. G. As Mudanças Climáticas: Riscos e Oportunidades. Água Brasil, 2015.

NEPSTAD, D. C.; STICKLER, C. M.; SOARES-FILHO, B.; MERRY, F.

Interactions among Amazon land use, forests and climate: prospects for a nearterm forest tipping point. Philosophical Transactions of the Royal Society

B: Biological Sciences, [s. l.], n. 363, p. 1737-1746, 2008.

NISHI, M. H.; JACOVINE, L. A. G.; SILVA, M. L.; VALVERDE, S. R.; NOGUEIRA, H. P.; ALVARENGA, A. P. Influência dos Créditos de Carbono na Viabilidade Financeira de Três Projetos Florestais. Revista Árvore, Viçosa, v.29, n.2, p. 263-270, 2005.

NOBRE, C. A.; MARENGO, J. A.; SOARES, W. R. Climate Change Risks in Brazil. Geneve: Springer, 2019.

OBSERVATÓRIO DO CLIMA. Mercado de carbono.Observatório do Clima,[s. l.], 2015. Disponível em: https://www.oc.eco.br/mercado-decarbono/. Acesso em: 16 jan. 2021.

OLIVEIRA, E. B.; RIBASKI, J.; ZANETTTI, É. A.; PENTEADO JUNIOR, J. F. Produção, carbono e rentabilidade econômica de Pinus elliottii e Eucalyptus grandis em sistemas silvipastoris no Sul do Brasil. Pesquisa Florestal Brasileira, [s. l.], n. 57, p. 45-56, 2010.

OVANDO, P.; BEGUERÍA, S.; CAMPOS, P. Carbon sequestration or water yield? The effect of payments for ecosystem services on forest management decisions in mediterranean forests. Water Resources and Economics, [s. l.], v. 28, p. 2212-4284, 2018. https://doi.org/10.1016/j.wre.2018.04.002 
PAIVA, D. S.; FERNANDEZ, L. G.; VENTURA, A. C.; ALVAREZ, G.; ANDRADE, J. C. S. Mercado voluntário de carbono: análises de co-benefícios de projetos brasileiros. Revista de Administração Contemporânea, Curitiba, v. 19, n. 1, p. 45-64, 2015.

PBMC. Mitigação das mudanças climáticas. Contribuição do Grupo de Trabalho 3 do Painel Brasileiro de Mudanças Climáticas ao Primeiro Relatório da Avaliação Nacional sobre Mudanças Climáticas Rio de Janeiro: PBMC: UFRJ, 2014.

PULVER, S.; HULTMAN, N.; GUIMARÃES, L. Carbon market participation by sugar mills in Brazil. Climate and Development, [s. l.], n. 2, p. 248-262, 2010.

RAMOS, D. P.; BITTENCOURT, F. R.; MITKIEWICZ, J. Cadernos IBRI: o mercado de carbono. São Paulo: IBRI, 2009 Disponível em: http://www.ibri. com.br/Upload/Arquivos/IBRI_Caderno_1.pdf. Acesso em: 25 jan. 2021.

REESON, A.; RUDD, L., ZHU, Z.Management flexibility, price uncertainty and the adoption of carbon forestry. Land Use Policy, [s. l.], v. 46, p. 267-272, 2015. https://doi.org/10.1016/j.landusepol.2015.02.016

SALLES, G. P.; SALINAS, D. T. P.; PAULINO, S. R.Execução de projetos de REDD+ no Brasil por meio de diferentes modalidades de financiamento. RESR, Piracicaba, v. 55, n. 3, p. 445-464, 2017.https://doi.org/10.1590/123456781806-94790550302

SANTANA FREIRE, R.; BRITO, A. M. V. G. Perspectives on the Implementation of Climate Change Public Policies in Brazil. In: GRAMMELIS, P. (Ed.). Green Energy and Technology, Geneve: Springer, 2016. 13-20.

SANTELLI, A. O que é o mercado de carbono e como o Brasil pode se beneficiar com ele. National Geographic, São Paulo, 2020. Disponível em: https://www.nationalgeographicbrasil.com/meio-ambiente/2020/02/o-quee-o-mercado-de-carbono-e-como-o-brasil-pode-se-beneficiar-com-ele. Acesso em: 05 maio 2021.

SANTOS, R. F; VIVAN, J. L. Pagamento por serviços ecossistêmicos em perspectiva comparada: recomendações para tomada de decisão. Brasília, DF: Projeto Apoio aos Diálogos Setoriais UE-Brasil, 2012.

SOUZA, A. L. R.; ALVAREZ, G.; ANDRADE, J. C. S.Mercado regulado de carbono no Brasil: um ensaio sobre divergências contábil e tributária dos créditos de carbono. Organizações e Sociedade, Salvador, v. 20, n. 67, p. 675-697, 2013. 
ST-LAURENT, G. P.; HAGERMAN, S.; HOBERG, G. Emergence and influence of a new policy regime: the case of forest carbon offsets in British Columbia, Canada. Land Use Policy, Vancouver, v. 60, p. 169-180, 2017. TORRES, C.; FERMAM, R.; SBRAGIA, I.CDM Projects in Brazil: market opportunity for companies and new designated operational entities. Ambiente \& Sociedade, São Paulo, v. 55, n. 3, p.445-464, 2016.

UNFCCC. Kyoto Protocol Reference Manual on Accounting of Emissions and Assigned Amount. Information Services of the UNFCCC Secretariat. Germany, 2008.

UNFCCC. Mechanisms Under the Kyoto Protocol. United Nations

Framework Convention on Climate Change, Bonn, 2021. Disponível em: https://unfccc.int/process/the-kyoto-protocol/mechanisms. Acesso em: 21 abr. 2021.

UNCC. About de UN Climate Change Conference - December 2019.United Nations Climate Change,Bonn, 2020. Disponível em: https://unfccc.int/ about-the-un-climate-change-conference-december-2019.

Acesso em: 06 mar. 2020.

VAN DER GAAST, W.et al. A contribuição dos projetos de crédito de carbono florestal para enfrentar o desafio das mudanças climáticas. Climate Policy, [s. l.], v. 18, n. 1, p. 42-48, 2018.

ZANETTI, E. A. Mudanças climáticas globais, florestas e mercado de carbono. Dia de Campo, Curitiba, 2013. Disponível em: http://www.diadecampo.com. br/arquivos/materias/\%7B233257306-104D\%7D_Mudancas_Climaticas_ Globais_Florestas_Madeira_e_Carbono.pdf Acesso em: 10 jul. 2019. 
